\title{
Impact of 2010 Floods on Pakistan’s Agriculture
}

\author{
Syed lazaz Ahmad Bukhari ${ }^{1 *}$ and Shahid Hassan Rizvi ${ }^{2}$
}

${ }^{1}$ The Islamia University of Bahawalpur, Lahore, Pakistan

${ }^{2}$ Department of Pakistan Studies and History, The Islamia University of Bahawalpur, Lahore, Pakistan

\begin{abstract}
Since 1929, 2010 flood have been assessed as the most horrible flood. It damaged standing crops over an area of 1.93 million acres. During 2010 floods 80 percent of the population in the flood-affected areas was depending upon agriculture for their livelihood. The floods and flash rains in the country have not only damaged agriculture crops, livestock, fisheries, and forestry, but have also destroyed primary infrastructure such as tube wells, water channels, household storages, houses, animal sheds, personal seed stocks/fertilizers, various agriculture machinery and equipment and many more. It has been estimated that the agriculture sector has experienced the overall damages of about Rs. 429 billion while cropped agriculture had suffered from 89 percent of these damages and losses. Productivity of cotton crop reduced to 11.76 million bales against the expected output of 14 million bales. The damages to livestock sector were estimated as of Rs. 48 billion. Damages to the fisheries were negligible and to the forestry were none. The present study is an attempt to explore the shocking impact of 2010 flood on agriculture. The prices of the basic agriculture inputs- diesel, urea, and pesticides- rose sharply. Diesel prices in June 2010 were 75.7 per liter while these prices reached the level of 94.1 per liter in June 2011. The study also tries to identify where man is consciously involved and where unconsciously -lack of planning, mismanagement, and lack of resources- causing floods. The study also tries to suggest how we can protect Pakistan from such hazards in future.
\end{abstract}

Keywords: Inundation; Magnitude; Merciless; Damages; Mismanagement

\section{Introduction}

The present study is an attempt to critically evaluate the shocking impact of floods on Pakistan. Pakistan is a climate sensitive country as its economy is agro-based and in Pakistan major flooding is associated with the heavily moist winds originating from Bay of Bengal [1]. The average annual rainfall varies from place to place such as mean annual rainfall of southern Punjab and northern Sindh is around $150 \mathrm{~mm}$ while there's $1500 \mathrm{~mm}$ of mean annual rainfall in northern mountainous region and upper Punjab [2]. Apart from all of this around 60-80 percent of annual precipitation occurs during a summer monsoons (July-September) period of three month. Due to Pakistan's specific geographical location, expected increase in country's average temperature is higher than global averages [3]. Pakistan has been passing through a stage of unplanned industrialization and urbanization. For a country, it's assumed that at least $25 \%$ of its area must be covered by forest. The area of Pakistan covered by forest is already very less which just $4.4 \%$ of its total area. On other hand, the country is experiencing highest the rate of deforestation (2\% per annum) over the globe [4]. During 2010, heavy monsoon rains, melting of snow and glaciers added such a massive volume of water into the Indus river system that surpassed all the historical flood records of the country [5]. In KPK, Kabul and Swat rivers two western tributaries of Indus River experienced record high flows about 400,000 cusecs [6]. Tunsa barrage recorded high flow of 960,000 cusecs. Guddu Barrage in between 8 and 9 August, 2010 registered a flood peak of 1,149,000 cusecs that is a record flow at Guddu Barrage since last 500 years [7]. As valley storage is limited so during wet years like during 2010 water channels could not hold most part of water and caused flooding (Table 1).

\section{Methodology}

Both qualitative and quantitative methods were adopted to resolve the problems, For the purpose questioner was designed and random sampling method was used to collected data from severely flood affected districts. As a basic source of data collection, "Quantitative Informants Interviews" were also conducted. Interviews were conducted; from the persons who have been the eye-witness of most of the flooding events,
Government officials, the relief workers, doctors working at the relief camps and NGOs representatives. Interviews were also made with the WAPDA spokesmen to get an insight into the situation. The overall data obtained was carefully examined and compared with the science based reasons for the flooding. Self-observations and photography along with information displayed by prominent T.V channels and concerned documentaries proved to be a great source of information to reach reliable findings. During July-September 2010, data from most of the available local as well international daily newspapers was extracted. Numerous studies have also been thoroughly reviewed for the purpose to justify and make the under-discussion topic interesting This study focuses on critical analysis of floods in Pakistan and tries to find the impact of major flooding events.

\section{Review of Literature}

For many reasons, the last four decades (1970-2010) have been demoralizing and sad one for the people of Pakistan. The floods in the history of Pakistan (1973, 1976, 1988, 1992 and 2010) have always brought with them disturbances for the soc-economic sectors. Various studies related to flooding in Pakistan clearly mention that the intensity and incidence of floods has increased during recent times. July-August 2010 flood is a practical example of this claim.

Dr. Muhammad Hanif, in his report on the topic of: Redistribution of Precipitation (Seasonal Shift) in Pakistan and Super Flood in Pakistan-2010, gives detailed elaboration of Weather Forecasting System

*Corresponding author: Syed lazaz Ahmad Bukhari, The Islamia University of Bahawalpur, Ex-Assistant Professor SPS, and Ex-Faculty Member Aitchison College, Lahore, Pakistan, Tel: +923366845466; E-mail: iazaz.bukhari@yahoo.com

Received November 18, 2016; Accepted December 19, 2016; Published January 03, 2017

Citation: Bukhari SIA, Rizvi SH (2017) Impact of 2010 Floods on Pakistan's Agriculture. J Environ Anal Toxicol 7: 424. doi: 10.4172/2161-0525.1000424

Copyright: ( $) 2017 \mathrm{Hu} \mathrm{B}$, et al. This is an open-access article distributed under the terms of the Creative Commons Attribution License, which permits unrestricted use, distribution, and reproduction in any medium, provided the original author and source are credited. 


\begin{tabular}{|c|c|c|c|c|}
\hline S. No & $\begin{array}{c}\text { Storage/ } \\
\text { Reservoir }\end{array}$ & $\begin{array}{c}\text { Original Gross } \\
\text { Storage (MAF) }\end{array}$ & $\begin{array}{c}\text { Storage Loss } \\
\text { till year 2003 } \\
\text { (MAF) }\end{array}$ & $\begin{array}{c}\text { Storage loss 2010 } \\
\text { (projected) (MAF) }\end{array}$ \\
\hline 1 & Tarbela & $11.62(1974)$ & $3.14(27 \%)$ & $3.95(34 \%)$ \\
\hline 2 & Chashma & $0.87(1971)$ & $0.37(43 \%)$ & $0.48(55 \%)$ \\
\hline 3 & Mangla & $5.88(1967)$ & $1.18(20 \%)$ & $1.60(27 \%)$ \\
\hline
\end{tabular}

(Source: Medium Term Development Framework 2005-2010 planning Commission GoP)

Table 1: Present water storage capacity available in Pakistan.

of PMD where he has thrown light on short range, medium range and seasonal weather forecasts and their chances of accuracy. Sare Laerke, in her PhD Thesis entitled as: "Ensuring a Sustainable Development within a Changing Climate", discusses that various methods and techniques must be used to prevent and mitigate climatic hazards such as floods.

Kazi Saeed Ahmad, in his article entitled as, "Climatic Regions of West Pakistan" is of the opinion that better understanding of climatic issues may help to fight against climatic hazards such as floods. A Report of Judicial Flood Inquiry Tribunal on the causes of major breeches in River Indus during the "exceptionally high floods," of 2010, was prepared under the chairmanship of Justice Syed Mansoor Ali Shah. With the title of: "A Rude Awakening". Annual Report 201011 by Pakistan Institute of Development Economics also focuses on "reactive" approach. Preliminary Rapid Damage Assessment in the Agriculture Sector for the flood affected areas of Pakistan. The structure and system of NDMA in the country focuses on to mitigate floods, it also provides rescue, relief and rehabilitation facilities. NDMA Annual Reports (2010, 2011 and 2012) discuss disaster management system in Pakistan like organizational structure of NDMA, and its response to major disasters in Pakistan. Federal Flood Commission (FFC) it was established in January 1977. FFC has organized and implemented three National Flood Protection plans since 1978, covering period from 197888 (NFPP-I), 1988-1998 (NFPP-II), and 1998-2008 (NFPP-II). These are the just a few examples of literature review not the complete picture of literature review.

\section{Results and Discussion}

The growth of agriculture sector recorded as 1.2 percent during 2010-11. The July-August flood 2010 submerged the most fertile and productive part 17 million acres of cultivated land [8]. This was the most fertile and productive part of the country, this region can be termed as "food as well economic basket" of the country. The affected region comprises of $16 \%$ of the agricultural land of the country [7]. This part of the country is famous for the cultivation of crops, vegetables, fruit farming, and fodder crops. The overall loss to the agriculture was documented as Rs. 429 billion [9]. Highest losses in terms of crops cultivation was recorded in Punjab (661 637 hectares) followed by Sindh (357 372 hectares), KPK (191 020 hectares) and PAK (92 370 hectares) [10] (Table 2).

This region is also famous for commercial live-stock farming as well for the large-scale production of dairy products. After 2010 flood an inflation of more than 18 percent was recorded for the food items [11]. This was obviously due to severe damages to the standing crops and massive killing of live-stock. As a result of 2010, summer flood, it was reported that 274334 domesticated animals died while rest of the animals were suffering from the shortage of feed and fodder. Reasonable quantity of feed and fodder is essential not only for the health of these animals but also for obtaining better production of dairy productsmilk, meat, butter, and yogurt- from these animals. This became much more important under conditions, when another 427,000 domesticated animals were suffering from diseases and starvation [12]; ultimately their lives were in great danger at that time. The death of remaining livestock clearly meant for a severe shortage of food products and economic loss for the flood affected community of the country.

Dr. Shahid Hassan Siddiqui (Economist and Scholar) in an interview on September 10, 2010 claimed that the current wave of inflation is artificial and has been injected to the country's economy by the poor policies, corruption, and mismanagement of the government officials:

In Pakistan, corruption is causing an annual loss of Rs. 900 billion to the country's economy; due to non-payment of taxes the country's economy is bearing a loss of Rs. 750 billion ever year while there could be a reduction of Rs. 75 billion in non-developmental charges very easily, every year. By resolving these issues, we can help flood affected community very easily; the higher wave of inflation would no more exist as a result of floods. But unfortunately, both the issues are related to big guns of the country. These are the people who are big land lords (big landlords of Pakistan are 7 percent and hold 43 percent of the country's lands) businessmen and industrialists. These are at key positions of the country and are not answerable to anyone. These people take loans from Banks and never pay back. If the government of our country is able to resolve above mentioned three issues, our country can resolve most of the problems of flood affected community by its own resources instead of begging for aid and taking foreign loans at harder conditions (Table 3).

This severe shortage of food items created a higher demand for these items in the market which resulted in the selling of sub-standard food items, black marketing, and higher prices of these food items in the market. The sharp increase in the prices of agricultural inputs was also observed during the period. The prices of the basic agriculture inputsdiesel, urea, and pesticides- rose sharply. Diesel prices in June 2010 were 75.7 per liter while these prices reached the level of 94.1 per liter in June 2011 [6]. There was an increase of Rs. 18.4 per liter with in a period of just one year. The same was the case for another agriculture input urea. Urea prices for a $50 \mathrm{~kg}$ urea bag were Rs 850 in November 2010 and urea prices for the same bag reached the limit of Rs. 1800 [10]. This situation increased the suffering of flood affected community on one hand as they have been ruined by the hands of floods, on other hand the prices of agricultural inputs and the prices of food items they have had to purchase for the survival of their families were touching the sky.

\begin{tabular}{|c|c|}
\hline Province/ Region & Crops destroyed (Area/hectares) \\
\hline Khyber Pakhtunkhwa & 443,116 \\
\hline Azad Jammu and Kashmir & 75,676 \\
\hline Punjab & 1.517 million \\
\hline Sindh & 998,561 \\
\hline Baluchistan & 627,992 \\
\hline
\end{tabular}

Source: All figures are based on FAO statistics.

Table 2: Damages to Standing Crops in the flood affected Regions.

\begin{tabular}{|c|c|c|c|c|c|}
\hline Livestock & Punjab & Sindh & KPK & Baluchistan & Total \\
\hline Died in Floods & 62765 & 54064 & 105042 & 51740 & 274334 \\
\hline Indirectly Affected & 4361000 & 7376115 & 739429 & 1621144 & 1432588 \\
\hline $\begin{array}{c}\text { Animal Sheds } \\
\text { Destroyed }\end{array}$ & 10700 & 33000 & 1900 & 800 & 46400 \\
\hline Fisheries & 916 & - & 23 & - & 939 \\
\hline Poultry farms/birds & 459000 & - & - & - & 459000 \\
\hline $\begin{array}{c}\text { Govt. Veterinary } \\
\text { centers }\end{array}$ & 13 & - & - & - & 13 \\
\hline
\end{tabular}

(Source: Field survey conducted during, July-September, 2010 in' 29' severely flood affected districts of Pakistan)

Table 3: Pakistan's 2010 Flood and its impact on Live-Stock (heads) and related infrastructure (B). 
Under these circumstances when they have to care for physically and mentally ill family member. On the basis of official record, the flood affected community must have to care for 2697 injured persons all over the country. Among these injured people, 98 were from Baluchistan, 1,193 were from KPK, 350 were from Punjab, 909 from Sindh, 60 from Gilgit-Baltistan (GB) and 87 from AJK. Affected community also has to find the replacements of 1,985 dead persons to carry out the circle of life on its normal routine [12].

A 51-year-old, respondent, Musa Khan from Noshera (KPK), 49 years old Din Muhammad from Rahim Yar Khan (Punjab) and 54 years old Gunaksi Devi from Khairpur (Sindh) expressed their concerns as follows:

"Our children are suffering from diseases; they are getting weaker and weaker but needed food for ill persons and medicines are not available at camps. The medicines that are available at camps are doing nothing to our patients."

When question about the mental health of the flood affected children was put forth in front of 800 respondents belonging to agricultural family's 35 percent accepted that their children are suffering from phobias, nightmares, and psychological problems. Now question is that a farmer who has lost most of his belongings as a result of flood. To visualize the economic worries of affected farmers, we must know that the flood affected 17,553 villages, also damaged 1.6 million houses. On the basis of these hard realities place yourself at the place of a farmer who is fighting against serious social as well economic issues not directly related to agriculture. Now, do you think such a person at the end of season may give you his maximum? If you're thinking so, I must salute your optimistic approach [13].

On one hand flood presented the gift of severe shortage of cereal crops and dairy products, on other hand it also affected cash crop farming. For instance, cotton crop showed a negative trend as it production declined from 12,913 thousand bales (2009-10) to 11,460 thousand bales (2010-11). The production of rice crop fell from 6,883 thousand tons (2009-10) to 4,823 thousand tons (2010-11). But the Wheat crop showed a bit improvement as its production improved from 23,311 thousand tons (2009-10) to 24,214 thousand tons (201011). The production of gram crop fell from 562 thousand tons (200910) to 523 thousand tons (2010-11) [14]. The production of maize crop showed an improvement as it increased from 3,262 thousand tons (2009-10) to 3,341 thousand tons (2010-11) (Table 4).

The increase in wheat production was mainly due to alluvium brought by flood waters on to the land which changed the less fertile soil in to a soil rich of much needed nutrients for the proper growth of crop. The reason for increase in maize production was that it was mainly cultivated over the areas that were mostly safe from flooding. Another reason behind increase in wheat production was that the government of Pakistan was very anxious about the cultivation of wheat as during flooding 2010, a lot of wheat stored by the government as well by the people had lost. So, the government provided standard agricultural

\begin{tabular}{|c|c|c|}
\hline Commodity & $\mathbf{2 0 0 9 - 1 0} \mathbf{( 0 0 0 )}$ & $\mathbf{2 0 1 0 - 1 1 ( 0 0 0 )}$ \\
\hline Cotton & 12,913 bales & 11,460 bales \\
\hline Rice & 6,883 tons & 4,823 tons \\
\hline Grams & 562 tons & 523 tons \\
\hline Maize & 3,262 tons & 3,341 tons \\
\hline Wheat & 23,311 tons & 24,214 tons \\
\hline
\end{tabular}

Source: Economic Survey of Pakistan 2010-11

Table 4: Showing, production of different commodities during 2009-10 and 2010-11. input like seeds, chemical fertilizers free of cost. At the same time farmers whom have had lost about everything, took this opportunity as a task and put their every effort to get the maximum output from their farm lands $[15,16]$. But, for the cultivation of wheat ideal conditions were not prevailing all over the flood affected areas as in different parts of the flood affected regions either the land was too wet to cultivate or was covered with infertile layers of rock particles so cultivation of crops was nearly impossible. Although, whole farm lands could not be used for the cultivation of wheat yet by the hard work of farmers and by the in-time efforts of the government and non-government organizations, the country was able to achieve a better production of wheat in 2010-11 in comparison to 2009-10 [17].

One, reason behind the lowering down of production of cotton, sugarcane and rice is that these crops have been cultivated with main canals diverted from rivers. As 19434 canals, have been damaged due to banks erosion, sedimentation, or siltation due to flooding, So, now, these canals need immediate de-silting, repair or reconstruction.

July-August floods of 2010 not only brought destructions and damages for the crops and live-stock but also brought economic as well social difficulties particularly for the big land lords as well for the medium scale farmers. Both suffered from economic challenges as they lost crops worth millions of rupees and this was a great economic setback for this section of rural community with white collar standing in the society [18]. Due to their standing in the society it was about impossible for these people to align with small scale and landless farmers. They also felt ashamed, against their dignity, honor and standing in the society to get any sort of in-kind support- free of cost chemical fertilizers and seeds- from the government or any NGO (nongovernmental organization) [19].

\section{Conclusion}

But the most ill-fated aspect related to our country is that we have not worked out a system that may help us to achieve the goal of sustainable development. Even if there is a bolt from the blue in the form of disasters such as intense flooding events like that of 1973, 1988, 1992 and 2010. There is also evidence from a number of studies that for attaining sustainable development there must be balance between ecological, economic, and social issues. For the reason, safety from floods is essential. There are number of evidences from a number of studies that not even a single country on the globe could achieve the target of sustainable development without improved economy. Inequalities are the breeding grounds for economic problems. For Pakistan, economic growth is very low as well slow while inequalities are at their peak.

\section{References}

1. Kazi SA (1951) Climatic regions of west Pakistan. Pakistan Geographical Review 6: 1-22.

2. Afzaal M, Hussain A (2006) Numerical Simulation of Summer Monsoon Precipitation of 1992 over Pakistan. Pak J Meteorol 3: 57-67.

3. Zahid M, Rasul G (2011) Frequency of extreme temperature and precipitation events in Pakistan 1965-2009. Sci Int 23: 313-319.

4. Naheed G, Rasul G (2011) Investigation of rainfall variability for Pakistan. Pak J Meteorol 14: 53-62.

5. Chaudhry QZ, Rasul G (2007) Global Warming and Expected snowline shift along Northern Mountains of Pakistan. In Proceedings of $1^{\text {st }}$ Asiaclic symposium, Yokohama, Japan

6. Ahmad F, Kazmi SF, Pervez T (2011) Human response to hydro-meteorological disasters: A case study of the 2010 flash floods in Pakistan. Journal of Geography and Regional Planning 4: 518. 
7. Hanif M (2010) Redistribution of Precipitation (Seasonal Shift) in Pakistan and Super Flood in Pakistan-2010, Islamabad: National Weather Forecasting Centre PMD, 02-67.

8. NDMA (2010) Annual Report 2010. Islamabad: Prime Minister's Secretariat, Islamabad, Pakistan, Pp: 02.

9. NDMA (2010) National Disaster Risk Management Framework Pakistan, Islamabad: National Disaster Management Authority Government of Pakistan, Pp: 1-91.

10. Khan AN (2010) A Brief Report on Activities of CDPM in Floods 2010, Islamabad: Centre for Disaster Preparedness and Management University of Peshawar, Pp: 1-12.

11. Hicks MJ, Burton ML (2010) Preliminary Damage Estimates for Pakistani Flood Events, 2010. Center for Business and Economic Research, Ball State University.

12. Government of Pakistan (2011) Unprecedented Floods and its Impact on the Fragile Economy of Pakistan, Islamabad: Director General of Training and Research. Pp: 10.
13. Tribunal JFI (2010) A rude awakening: Report of the Judicial Flood Inquiry Tribunal on the causes of the major breaches in River Indus during the "exceptionally high floods" of 2010.

14. Dixit A (2003) Floods and vulnerability: need to rethink flood management Natural Hazards 28: 155-179.

15. Lamond JE (2008) The impact of flooding on the value of residential property in the UK. University of Wolverhampton.

16. Laerke S (2010) Ensuring a Sustainable Development within a Changing Climate. Unpublished Ph. D. thesis, University of Copenhagen, Denmark, Pp: 1-136.

17. Government of Pakistan (1994) Flood Forecasting System in Pakistan and its Limitation, An unpublished report of National Flood Forecasting Bureau and Pakistan Meteorological Department Lahore, Pakistan, Pp: 16.

18. Government of Pakistan (2010) National Disaster Response Plan (NDRP) Islamabad: National Disaster Management Authority Prime Minister's Secretariat Pp: 23.

19. Zenklusen O (2007) Natural Disasters and Economic Development: A Neoclassical Review of Theoretical Perspectives and Empirical Evidence. Unpublished PhD Thesis, University of St. Gallen, Germany, pp: 1-261. 